\title{
Study on a Novel Water-Soluble Hydrophobically Associating Polymer as an Enhanced Heavy Oil Recovery Agent
}

\author{
Dongyu Qiao, ${ }^{1}$ Zhongbin Ye $\mathbb{D}^{1,2}$ Xindong Wang, ${ }^{3}$ Yiping Zheng, ${ }^{3}$ Lei Tang, \\ and Nanjun Lai $\mathbb{D}^{1,2}$ \\ ${ }^{1}$ School of Chemistry and Chemical Engineering of Southwest Petroleum University, Chengdu, 610500 Sichuan, China \\ ${ }^{2}$ Oil \& Gas Field Applied Chemistry Key Laboratory of Sichuan Province, Chengdu, 610500 Sichuan, China \\ ${ }^{3}$ Engineer Technology Research Institute, CNPC Xibu Drilling Engineering Company Limited, Urumqi 830001, China
}

Correspondence should be addressed to Zhongbin Ye; yezb@swpu.edu.cn and Nanjun Lai; lainanjun@126.com

Received 8 September 2021; Accepted 30 September 2021; Published 3 November 2021

Academic Editor: Qingwang Yuan

Copyright ( 2021 Dongyu Qiao et al. This is an open access article distributed under the Creative Commons Attribution License, which permits unrestricted use, distribution, and reproduction in any medium, provided the original work is properly cited.

\begin{abstract}
In this study, emulsion-free radical reaction was applied to synthesize a novel sulfomethylating hydrophobically associating copolymer (HPDS) by using acrylamide, acrylic acid, $\mathrm{NaHSO}_{3}, \mathrm{HCHO}$, and a laboratory-made N,N-divinylnonadeca-1,10dien-2-amine to enhance heavy-oil recovery. The structure and properties of HPDS were characterized by a range of experiments, which showed that HPDS had better stability and enhanced heavy-oil recovery capacity than hydrolyzed polyacrylamide (HPAM). One-dimensional flooding experiments illustrated that HPDS performed better in establishing resistance factor $(\mathrm{RF})$ and residual $\mathrm{RF}(\mathrm{RRF})$, and approximately $19.8 \%$ oil recovery could be enhanced by injecting $1500 \mathrm{mg} / \mathrm{L}$ of HPDS solution compared with that of HPAM at only 14.1\%. HPDS has a promising application prospect in enhancing heavy-oil recovery.
\end{abstract}

\section{Introduction}

Heavy-oil reservoirs are one of the most important unconventional resources, with an enormous economic value and an abundant quantity of reserves. The application of thermal methods to enhance heavy-oil recovery has some crucial challenges due to economic and environmental obstacles $[1,2]$. For example, SAGD is a thermal process requiring energy to turn water into steam, and it is commercially expensive. In addition, fresh water supply is another environmental issue inhibiting the application of thermal methods $[3,4]$.

Water flooding is a commonly used secondary recovery method in the industry because it is economically advantageous for the development of oil reservoirs; however, more than $60 \%$ of the heavy oil in place is usually still left after the technique is conducted $[5,6]$. Polymer flooding is a technology wherein high-molecular-weight, water-soluble polymers are added to the injection water to increase the viscosity and reduce the mobility ratio of the injection water and the crude oil to be displaced [7, 8]. One of the most commonly used polymers is the partially hydrolyzed polyacrylamide (HPAM) due to its rapidly soluble and large hydrodynamic volume, which could greatly enhance solution viscosity. Given the high sensibility of the HPAM chain in aqueous solution at high temperature and high salinity, a considerable loss in viscosity is possible owing to its molecules' random/coil conformation $[9,10]$.

In recent years, several efforts have been exerted to develop new polymers with superior performance at high temperature and high salinity, and some progresses have been made $[11,12]$. Two approaches could be mainly used to make new polymers with preferable performance in harsh environments. The first is the introduction of hydrophobic groups [13-15]. An effective method to improve polymer salt tolerance and thermal stability is by increasing polymer hydrophobic interaction by introducing hydrophobic groups into the molecular chains. Polymers with hydrophobic groups exhibit similar viscosities in fresh and saline waters. The second is the introduction of salt-tolerant groups 
[16-18]. The carboxyl groups in HPAM could easily react with $\mathrm{Ca}^{2+}$ and $\mathrm{Mg}^{2+}$ ions in the solution and form precipitate, resulting in phase separation or formation damage. If $-\mathrm{SO}_{3} \mathrm{H}$ groups could be introduced to acrylamide (AM), the polymer could exhibit good thermal stability and increased tolerance with divalent and multivalent metal ions. In addition, the $-\mathrm{SO}_{3} \mathrm{H}$ group is a strong polar group, and its strong hydrophilic interaction and electrostatic repulsion increase the water solubility of copolymers and the fluid volume of the molecular chain [19-21].

Inspired by predecessors' methods, a novel thermal stable and salt-tolerant polymer referred to as HPDS was synthesized by introducing sulfonic acid groups to a watersoluble hydrophobically associating polymer referred to as HPDN, which was prepared from AM, acrylic acid (AA), and another laboratory-made agent $\mathrm{N}, \mathrm{N}$-divinylnonadeca1, 10-dien-2-amine (DNDA) in emulsion-free radical reaction. Then, a series of work was conducted to HPDS, such as characterization and performance testing.

\section{Experimental}

\subsection{Materials}

2.1.1. Drugs. AM was obtained commercially and purified by crystallization from a water-ethanol mixture. $\mathrm{NaOH}, \mathrm{AA}$, $\mathrm{NaHSO}_{3},\left(\mathrm{NH}_{4}\right)_{2} \mathrm{~S}_{2} \mathrm{O}_{8}$, alkylphenol ethoxylates (OP-10), $\mathrm{NaCl}, \mathrm{MgCl}_{2} \cdot 6 \mathrm{H}_{2} \mathrm{O}, \mathrm{CaCl}_{2}$, and other chemicals were commercially available and used directly without further purification. DNDA was prepared in accordance with literature $[22,23]$. Crude oil and HPAM came from Shengli Oilfield in Dongying (Shandong Province, China). Water was doubly distilled and deionized by passing through an ion exchange-column. All the other chemicals were of analytical grades, unless otherwise noted.

2.1.2. Instrument. WQF-520 infrared spectrometer (Beijing Rayleigh Analytical Instrument Co., Ltd.), Bruker AC-E 200 (Bruker BioSpin, Switzerland), S-3000 N scanning electron microscopy (SEM, Hitachi, Japan), Brookfield DV-III rheometer, HAAKE RheoStress 6000 rotational rheometer (Thermo Fisher Scientific, Waltham/Massachusetts), and Waring stirrer (LB20EG laboratory blender) were used in this study.

\subsection{Preparation of the HPDS. Copolymerization of HPDN} was carried out by emulsion-free radical polymerization. Seven grams of AM, $3 \mathrm{~g}$ of AA, $0.0361 \mathrm{~g}$ of DNDA, emulsifier (0.3 wt.\%), and $\mathrm{NaHSO}_{3}-\left(\mathrm{NH}_{4}\right)_{2} \mathrm{~S}_{2} \mathrm{O}_{8}$ initiator $(0.2 \mathrm{wt} . \%$ and $1: 1 \mathrm{~mol}$ ratio) were taken along with deionized water in a three-necked flask assembled with a nitrogen inlet. The reactor was kept in a water bath with magnetic stirring arrangement. Copolymerization was carried out at $40^{\circ} \mathrm{C}$ under $\mathrm{N}_{2}$ atmosphere for $10 \mathrm{~h}$. The $\mathrm{pH}$ of the reaction was 7 . The polymer was then isolated by precipitation with acetone or water-ethanol and dried in a vacuum oven at $40^{\circ} \mathrm{C}$ for $7 \mathrm{~h}$ to yield the corresponding copolymer.

A new sulfonylurea methylation modification displacing agent was synthesized through the reaction with $\mathrm{HCHO}$ and $\mathrm{NaHSO}_{3}$. HPDN dissolved to 1 wt.\% with deionized water was taken along with $\mathrm{NaHSO}_{3}$ and $\mathrm{HCHO}$ (7.5 wt.\% and $3: 1 \mathrm{~mol}$ ratio) in a three-necked flask assembled with a nitrogen inlet. The reactor was kept in a water bath with magnetic stirring arrangement. Reaction was carried out at $70^{\circ} \mathrm{C}$ under $\mathrm{N}_{2}$ atmosphere. The $\mathrm{pH}$ of the reaction was 11 . The polymer then was isolated by precipitation with acetone or water-ethanol and dried in a vacuum oven at $40^{\circ} \mathrm{C}$ for $7 \mathrm{~h}$ to yield the corresponding HPDS. The synthesis rout of HPDS is shown in Scheme 1.

\subsection{Characterization. HPDN and HPDS were characterized} by WQF-520 infrared spectroscopy. The ${ }^{1} \mathrm{H}-\mathrm{NMR}$ spectra of HPDS were recorded on Bruker AC-E 200 (Bruker BioSpin, Switzerland) spectrometer by dissolving the samples in $\mathrm{D}_{2} \mathrm{O}$ and being operated at $200 \mathrm{MHz}$.

HPDS was dissolved in degassed and distilled water (solution concentration $=2000 \mathrm{mg} / \mathrm{L}, \mathrm{HPAM}$ concentration $=2000 \mathrm{mg} / \mathrm{L}$ ) to observe the microscopic structures. SEM images were taken by S-3000 N SEM (Hitachi, Japan). The SEM resolution was $3 \mu \mathrm{m}$, and the magnifying multiple ranged from 3 to 30,000 . Analysis was conducted at $20 \mathrm{kV}$ acceleration voltage and $120-500 \mathrm{~Pa}$ pressure in the sample chamber.

2.4. Intrinsic Viscosity. The intrinsic viscosity [ $\eta$ ] of HPDS was measured with Ubbelohde's viscometer (diameter: $0.3 \mathrm{~mm}$, length: $12.15 \mathrm{~cm})$ at $30^{\circ} \mathrm{C}$. The solvent $(1 \mathrm{~mol} / \mathrm{L}$ $\mathrm{NaCl}$ ) efflux time was greater than $100 \mathrm{~s}$. Therefore, no kinetic energy corrections were made on the observed data. The temperature was controlled using a Cannon constanttemperature bath. Triplicate records were taken at each concentration using a stopwatch with an accuracy of $0.2 \mathrm{~s}$. At each concentration, the reduced viscosity $\left(\eta_{\mathrm{sp}} / c_{\mathrm{r}}\right)$ and inherent viscosity $\left(\ln \eta_{\mathrm{r}} / c_{\mathrm{r}}\right)$ were determined from the passing time of polymer solutions, and then, they were plotted against the concentration of polymer solutions. Extrapolation was used to gain the intercept $(H)$. Then, the inherent viscosity of HPDS was calculated using the following equation:

$$
[\eta]=\frac{H}{c_{0}},
$$

where $[\eta]$ is the intrinsic viscosity, $\mathrm{mL} / \mathrm{g} ; H$ is the intercept of $\mathrm{y}$ axis; and $c_{0}$ is the initial concentration of polymer solution, $\mathrm{g} / \mathrm{mL}$.

2.5. Viscosity in Different Concentrations. HPDS and HPAM solutions with different concentrations were established (polymer dilute solution was diluted by mother liquor, the same as below), and the apparent viscosities of the solutions were measured by Brookfield DV-III rheometer at $25^{\circ} \mathrm{C}$.

2.6. Rheology Test. The rheological properties of polymer solution are closely related to its solution properties. They are the integrated embodiment of solution's microphase structure and functions. Thus, the investigation of rheological property was repeatedly utilized to study whether the polymer solution met the requirement of the oil displacement in 
<smiles>C=CCN(CC=C)C(=O)CCCCCCC/C=C/CCCCCCC</smiles>

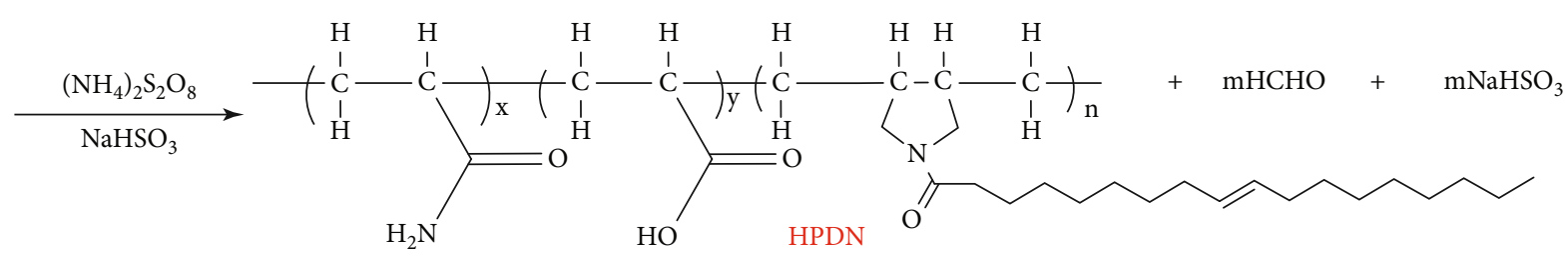

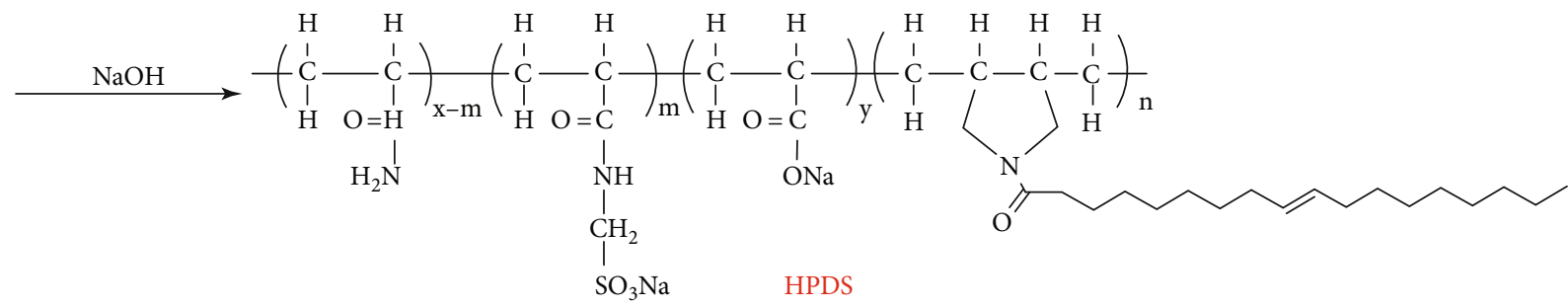

Scheme 1: The synthesis of HPDS.

previous studies. HAAKE RheoStress 6000 rotational rheometer (Thermo Fisher Scientific, Waltham/Massachusetts) was used to study the rheological character of the HPDS $(1500 \mathrm{mg} / \mathrm{L})$ and $\operatorname{HPAM}(1500 \mathrm{mg} / \mathrm{L})$ solutions at $30^{\circ} \mathrm{C}$.

2.7. Stability Experiments. When injected into the formation, the polymer solution could be subjected to different types of shearing, such as the shearing of pipelines and formation. Waring stirrer (LB20EG laboratory blender) was used to simulate the shearing in the injection process. Different concentrations of HPAM and HPDS were sheared for $30 \mathrm{~s}$ $(5000 \mathrm{r} / \mathrm{min})$ [24]. The viscosities of the polymers were determined after $30 \mathrm{~min}$.

Temperature rises as the depth of oil or gas well/reservoir increases, thus making the viscosity of the polymer flood agent decreased remarkably. Brookfield DV-III rheometer was utilized to measure the apparent viscosity of HPDS solutions $(1500 \mathrm{mg} / \mathrm{L})$ in comparison with that of HPAM solutions $(1500 \mathrm{mg} / \mathrm{L})$. Then, temperature resistance and salt tolerance were tested repeatedly with the increase in temperature and salinity.

2.8. Physical Simulation Experiments. Sand-pack models were used in the physical simulation experiments to test the capacity of HPDS to establish resistance factor (RF) and residual RF (RRF), which were the measurements of injectability and profile controlling. A single homogeneous core was present in the sand-pack model with a diameter of $2.5 \mathrm{~cm}$ and a length of $50 \mathrm{~cm}$. The permeability of the models was in the range of $2.0-3.0 \mu \mathrm{m}^{2}$ by packing with some quartz sand, which was washed by hydrochloric acid solution and distilled water several times. In the physical simulation experiment, the core was saturated with $5000 \mathrm{mg} / \mathrm{L} \mathrm{NaCl}$ brine. Then, $1500 \mathrm{mg} / \mathrm{L}$ polymer solution was injected until the pressure of the core was stable. Afterwards, water was injected into the core until the pressure became stable again $[25,26]$. The RF and RRF of the polymer solution were calculated using Equations (2) and (3), respectively, as follows:

$$
\begin{array}{r}
\mathrm{RF}=\frac{K_{\mathrm{w}} \mu_{\mathrm{p}}}{K_{p} \mu_{\mathrm{w}}}, \\
\mathrm{RRF}=\frac{K_{\mathrm{wa}}}{K_{\mathrm{wb}}},
\end{array}
$$

where RF and RRF are the resistance factor and residual resistance factor of the polymer solution, respectively; $K_{\mathrm{p}}$ and $K_{\mathrm{w}}$ are the permeability of polymer injection and water injection, $\mu \mathrm{m}^{2} ; \mu_{\mathrm{p}}$ and $\mu_{\mathrm{w}}$ are the viscosity of injected polymer and water, mPa.s; and $K_{\mathrm{wb}}$ and $K_{\mathrm{wa}}$ are the permeability before and after injection of polymer, $\mu m^{2}$.

The permeability of the sand-pack models was determined using Darcy's law as follows:

$$
K=\frac{\mu L Q}{\Delta P A},
$$

where $K$ is the permeability of the sand-pack model, $\mu m^{2}$; $\mu$ is the viscosity of the injected fluid, $\mu \mathrm{m}^{2} ; A$ is the inner cross-sectional area of the sand-pack model, $\mathrm{cm}^{2} ; Q$ is the flow rate of the fluid, $\mathrm{mL} / \mathrm{s} ; \Delta P$ is differential pressure, atm; and $L$ is the length of the sand-pack model, $\mathrm{cm}$. 


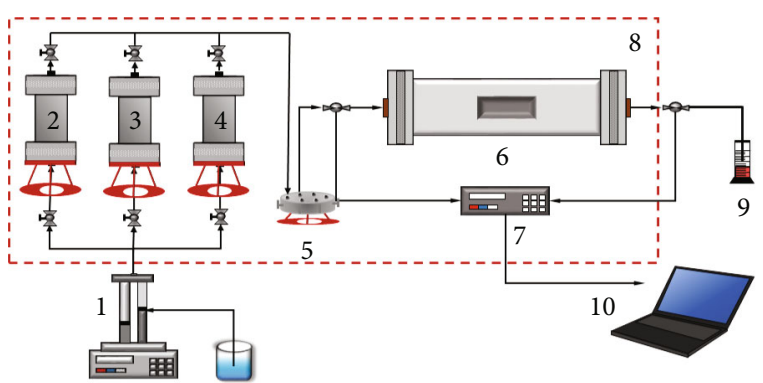

FIGURE 1: One-dimensional sand-packed model for EOR. 1: ISCO pump; 2: heavy oil; 3: polymer solution; 4: $\mathrm{NaCl}$ solution; 5: valves; 6: one-dimensional sand packed model; 7: pressure acquisition system; 8: constant temperature box; 9: sample device; 10: computer.

A two-layer model with two parallel homogeneous cores with different permeabilities was also utilized in the flooding experiments to simulate the nonhomogeneity of the reservoir. Every core had a diameter of $2.5 \mathrm{~cm}$ and a length of $25 \mathrm{~cm}$. The permeability of the two layers was in the ranges of $1.2-1.8$ and $0.4-0.6 \mu \mathrm{m}^{2}$, respectively. In the flooding tests, the two cores were saturated with $5000 \mathrm{mg} / \mathrm{L} \mathrm{NaCl}$ brine. Then, crude oil (apparent viscosity was $58.2 \mathrm{mPa} \cdot \mathrm{s}$ at $60^{\circ} \mathrm{C}$ ) was injected into the cores to saturate until no brine flowed from the end of the two cores. After aging (24h), brine was injected into the cores saturated with oil until the water cut reached $95 \%$. After the brine flooding, 0.3 pore volume $\left(V_{\mathrm{p}}\right)$ of polymer solution was injected into the twolayer model. Then, subsequent water continued to be injected until the water cut reached $95 \%$ again. All of the experiments were carried out at $60^{\circ} \mathrm{C}$. The injecting velocity of oil, brine, and flooding agent was $3 \mathrm{~mL} / \mathrm{min}$. The EOR of polymer solutions were calculated using Equation (5) as follows:

$$
\mathrm{EOR}=E_{\mathrm{P}}-E_{\mathrm{W}}
$$

where EOR is the enhanced oil recovery of polymer solution, $\%$; $E_{\mathrm{p}}$ is the total recovery of flooding process, \%; and $E_{\mathrm{w}}$ is the oil recovery of the water flooding process, \%. Figure 1 shows the equipment used in the flooding test.

\section{Results and Discussion}

3.1. IR Spectroscopy Analysis. The structure of HPDN and HPDS was confirmed by IR spectroscopy (as shown in Figure 2). In the IR spectrum, certain groups of chemical bonding gave rise to bands at or near the same frequency, regardless of the rest structure of the molecule. The major functional groups identified in the spectrum of HPDN included N-H stretching vibration $\left(3408 \mathrm{~cm}^{-1}\right)$ and $\mathrm{C}=\mathrm{O}$ deformation of the saturate $\left(1675 \mathrm{~cm}^{-1}\right)$. The peaks at 2945 and $2921 \mathrm{~cm}^{-1}$ indicated the presence of $-\mathrm{CH}_{2^{-}}$groups, and the peak of $\mathrm{C}$ double-bond stretching vibration appeared at $1660 \mathrm{~cm}^{-1}$. As expected, the IR spectra confirmed the presence of different monomers in the copolymer HPDN. The peaks at 630,1045 , and $1198 \mathrm{~cm}^{-1}$ indicated the presence of sulfonic acid groups. The IR spectrum of HPDN and HPDS indicated that sulfonic acid groups were successfully connected to the polymer chain as expected.

3.2. ${ }^{1} H$-NMR Analysis. The ${ }^{1} \mathrm{H}-\mathrm{NMR}$ spectra of HPDS are shown in Figure 3. The chemical shift value at $5.96 \mathrm{ppm}$ was assigned to the protons of $-\mathrm{NH}_{2}$. The protons of C-C double bonds appeared at $5.59 \mathrm{ppm}$, and the protons of $-\mathrm{CH}_{2}$ - in the $\alpha$-position to the sulfonic acid groups appeared at $5.57 \mathrm{ppm}$. The chemical shift value at near 3.41 and $3.39 \mathrm{ppm}$ could be assigned to the protons of $-\mathrm{CH}_{2}$ - of nitrogen heterocyclic ring. The broad signals at $2.11 \mathrm{ppm}$ could be attributed to methylene protons. The shift value near $1.11 \mathrm{ppm}$ was assigned to methyl. Other shift values at $1.11,3.57$, and $4.70 \mathrm{ppm}$ were assigned to the protons of $\mathrm{H}_{2} \mathrm{O}$ and ethanol. Thus, the ${ }^{1} \mathrm{H}-\mathrm{NMR}$ spectra of HPDS indicated that sulfonic acid groups and DNDA were successfully connected to the polymer chain as expected.

3.3. Environmental SEM (ESEM) Images. ESEM was utilized to study the morphology of the HPDS and HPAM solutions at concentrations of $1500 \mathrm{mg} / \mathrm{L}$. As shown in Figure 4, the observation accuracy of (a) and (b) was $20 \mu \mathrm{m}$, and the magnification of (a) and (b) was 5000 times. The network structure could be easily observed, and HPDS showed a stronger link and better dimensional network structure than HPAM due to the association action. The network structure could prevent further degradation of the molecular chains, hence more shear, temperature, and salt resistances.

3.4. Intrinsic Viscosity of HPDS. Intrinsic viscosity was measured in accordance with the previous experimental plan, and the result of HPDS was $388.15 \mathrm{~mL} / \mathrm{g}$. Figure 5 shows that the $\eta_{\mathrm{sp}} / c_{\mathrm{r}}$ and $\ln \eta_{\mathrm{r}} / c_{\mathrm{r}}$ of HPDS had a good linear relationship with $c_{\mathrm{r}}$. The $\eta_{\mathrm{sp}} / c_{\mathrm{r}}$ of general polymers decreases with the decrease in $c_{\mathrm{r}}$, and $\ln \eta_{\mathrm{r}} / c_{\mathrm{r}}$ increases with the decrease in $c_{\mathrm{r}}$. The $\eta_{\mathrm{sp}} / c_{\mathrm{r}}$ of HPDS decreased linearly with the decrease in $c_{\mathrm{r}}$, similar to the reported viscosity behavior of conventional polymer solutions.

3.5. Rheological Properties of Polymer. Rheological properties were investigated using HAAKE RheoStress 6000 rotational rheometer (as shown in Figure 6). The HPDS aqueous solution inherently showed better viscosity than the HPAM solution under the same concentration, indicating that the HPDS solution had a perfect property of retaining viscosity and strong non-Newtonian behavior.

3.6. Stability Experiments. The effect of concentration on the apparent viscosity of HPDS and HPAM solutions was determined (as shown in Figure 7). With the increase in polymer solution concentration, the apparent viscosity mounted, and the viscosity of HPDS was lower than that of HPAM before $1500 \mathrm{mg} / \mathrm{L}$. Meanwhile, with the accretion of polymer solution concentration, the apparent viscosity of HPDS solution sharply increased. At low concentrations, the association of polymer was mainly intramolecular association. When the concentration was greater than $\mathrm{CAC}$, the intermolecular association formed a transient network structure, which could increase the hydrodynamic radius of polymer. With 


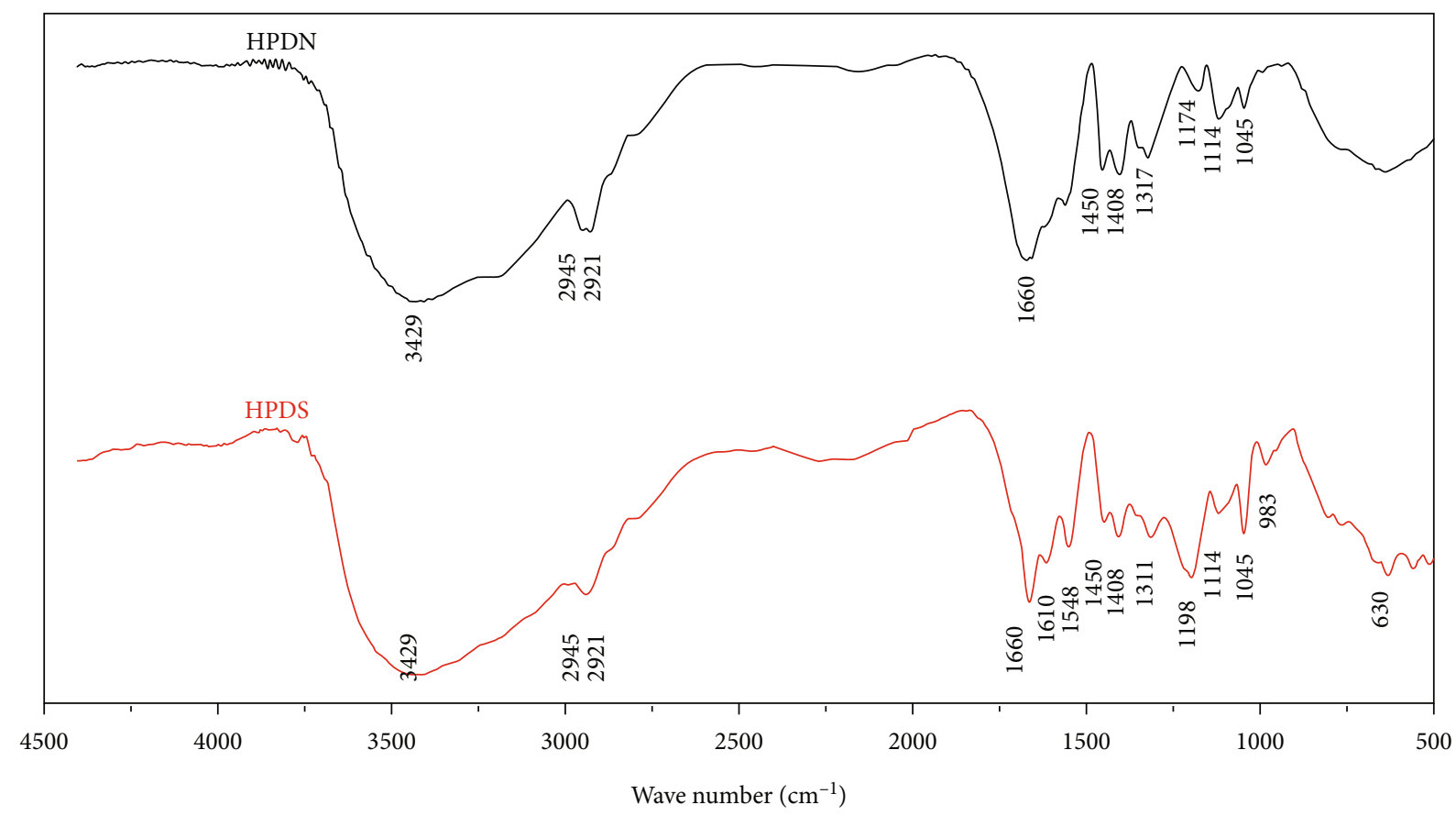

FIGURE 2: IR spectra of HPDN and HPDS.

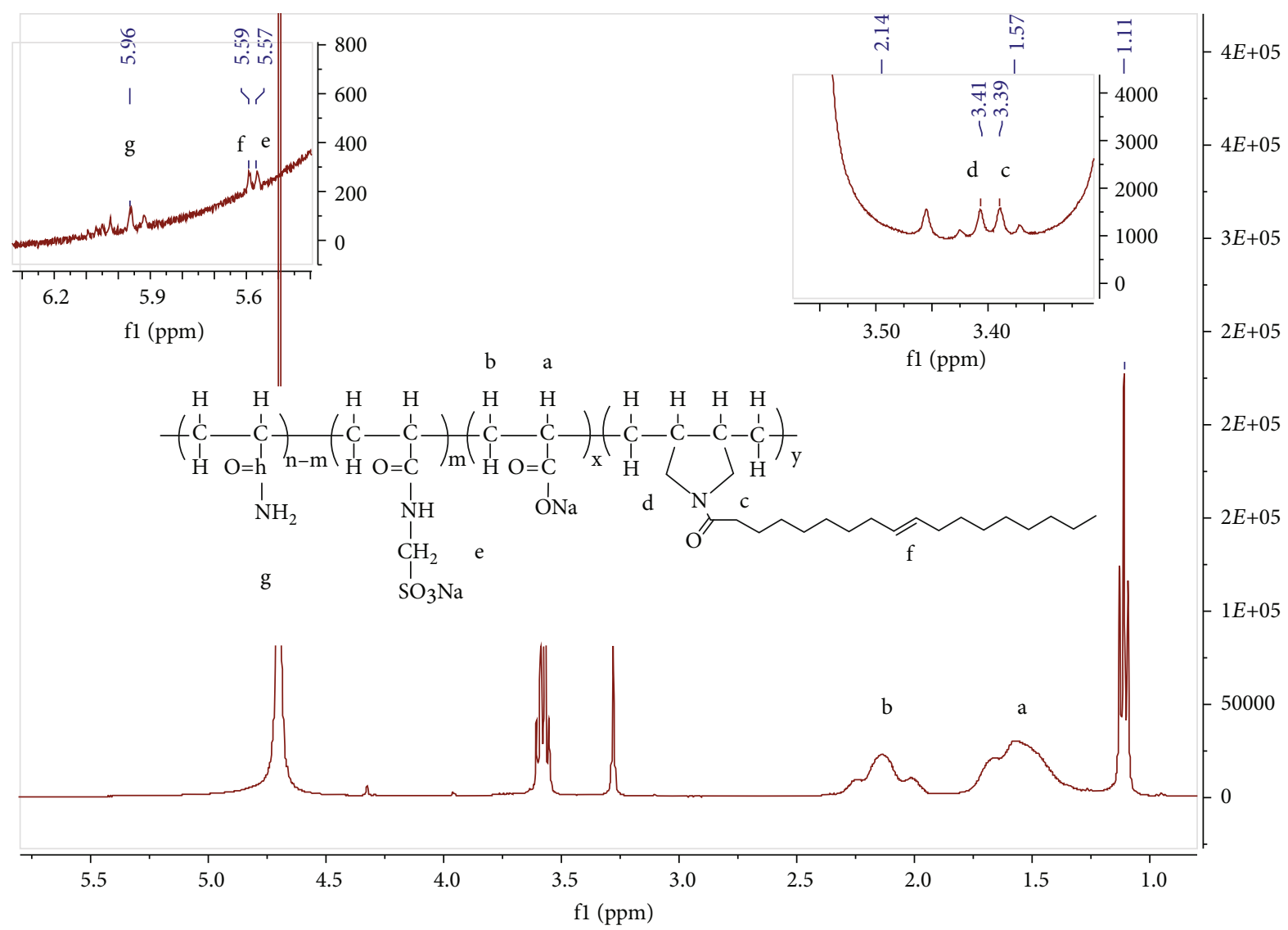

Figure 3: ${ }^{1} \mathrm{H}-\mathrm{NMR}$ spectra of HPDS. 


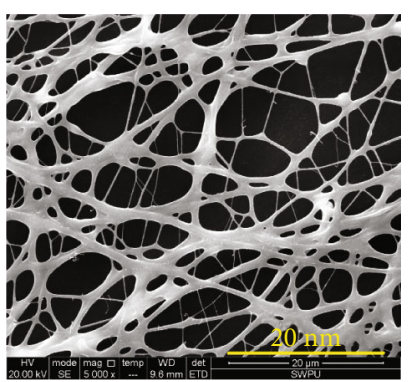

(a)

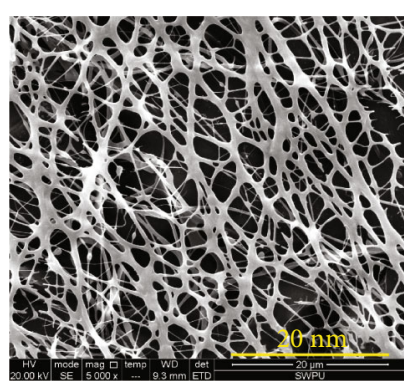

(b)

FIgURE 4: Structure of HPAM (a) and HPDS (b) solution.

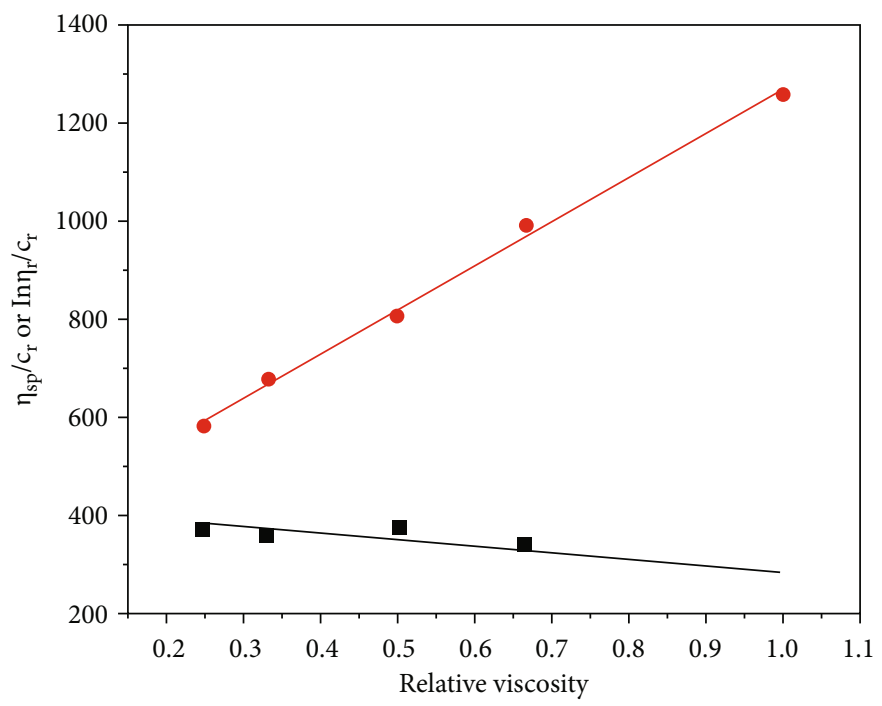

- In $\eta_{\mathrm{r}} / c_{\mathrm{r}}$

- $\eta_{\mathrm{sp}} / \mathrm{c}_{\mathrm{r}}$

FIgURE 5: Relationship between $\eta_{\mathrm{sp}} / c_{\mathrm{r}}$ or $\ln \eta_{\mathrm{r}} / c_{\mathrm{r}}$ and relative viscosity.

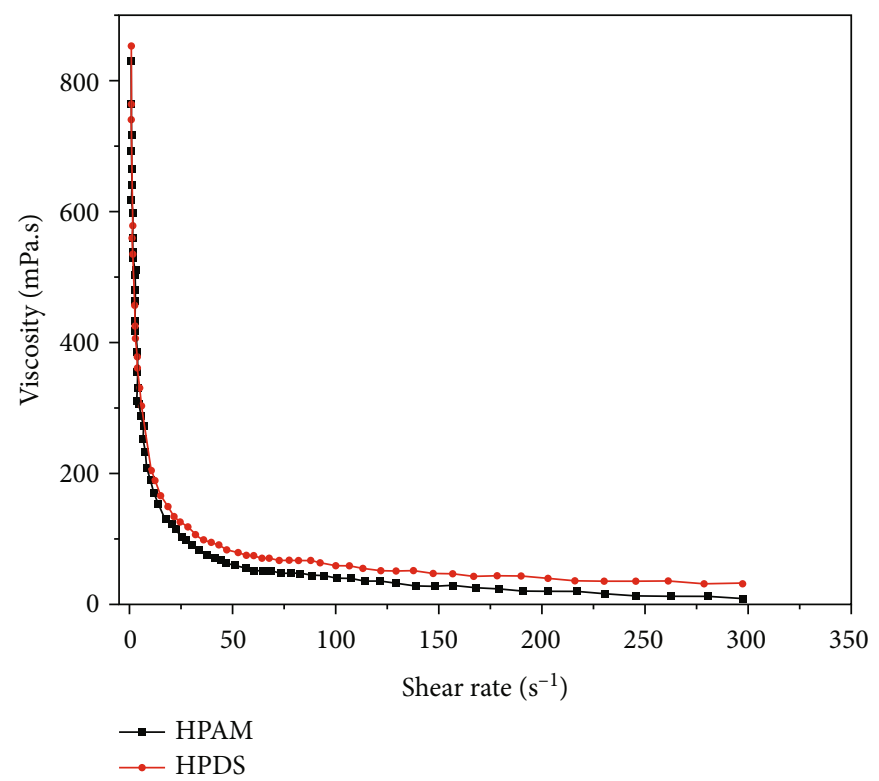

FIGURE 6: Relationship between apparent viscosity and shear rate. 


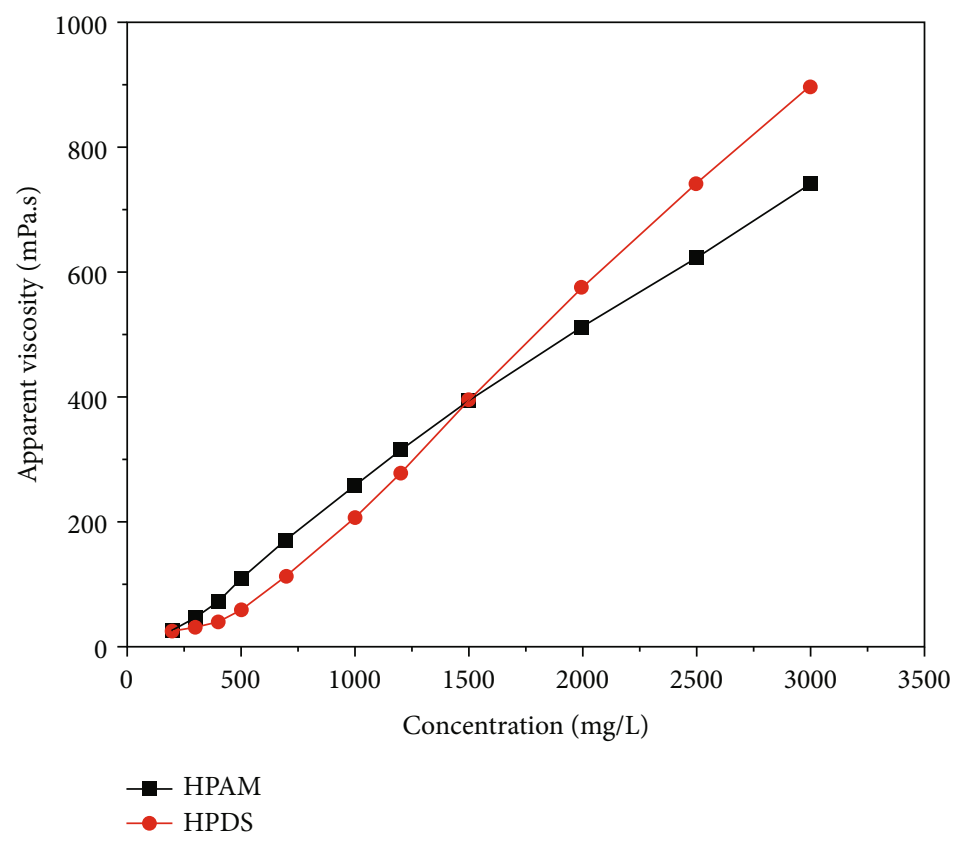

FiguRE 7: Relationship between apparent viscosity and concentration.

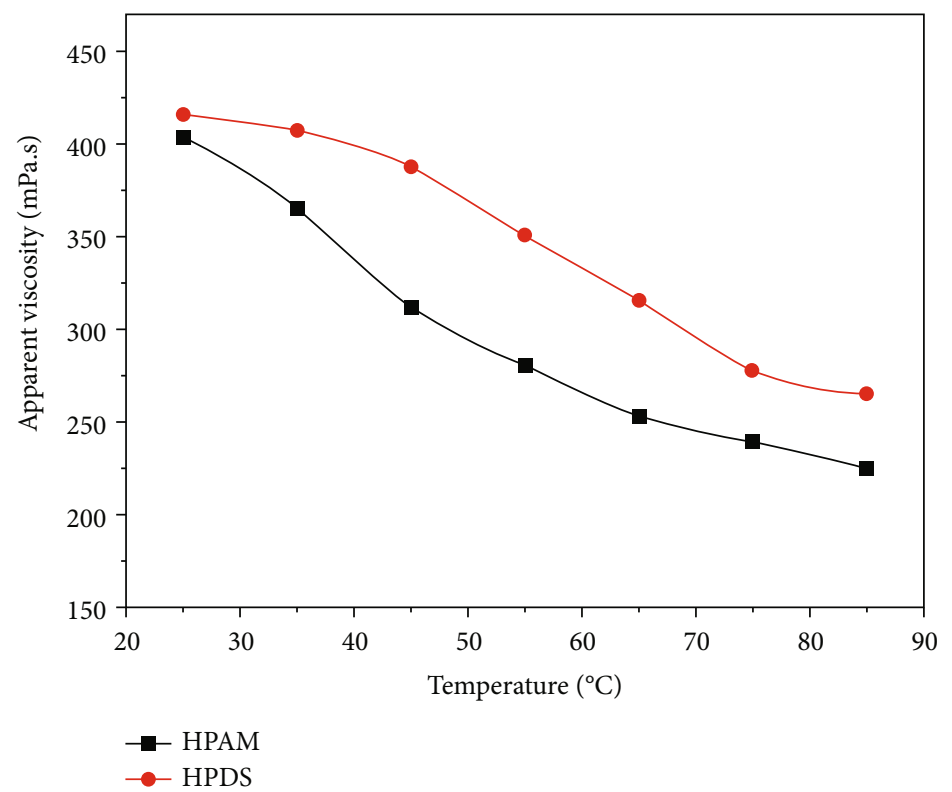

FIGURE 8: Relationship between apparent viscosity and temperature.

the further increase in concentration, the intermolecular association formed more intermolecular structures. Thus, the apparent viscosity of HPDS solution was much thicker. The critical association concentration was approximately $500 \mathrm{mg} / \mathrm{L}$ (as shown in Figure 7).

The effect of temperature on polymer solution was investigated (Figure 8). The general trend indicated an apparent viscosity decrease with increasing temperature. The phenomenon may be attributed to the effect of temperature. A large number of associating groups aggregate together to form reversible supermolecular structures via strong van der Wall's interactions, and polymer chains entangle with
TABLE 1: Data of HPDS and HPAM shear resistance test.

\begin{tabular}{lccccc}
\hline \multirow{3}{*}{ Shear conditions } & & \multicolumn{4}{c}{ Polymer concentration $(\mathrm{mg} /$} \\
& Polymer types & L) and viscosity (mPa·s) \\
& & 500 & 1000 & 1500 & 2000 \\
\hline \multirow{2}{*}{ Before shearing } & HPDS & 58.9 & 205.1 & 395.3 & 575.2 \\
& HPAM & 108.7 & 257.3 & 391.5 & 511.3 \\
After shearing & HPDS & 40.5 & 103.6 & 298.8 & 445.2 \\
& HPAM & 89.4 & 150.8 & 211 & 266.9 \\
\hline
\end{tabular}




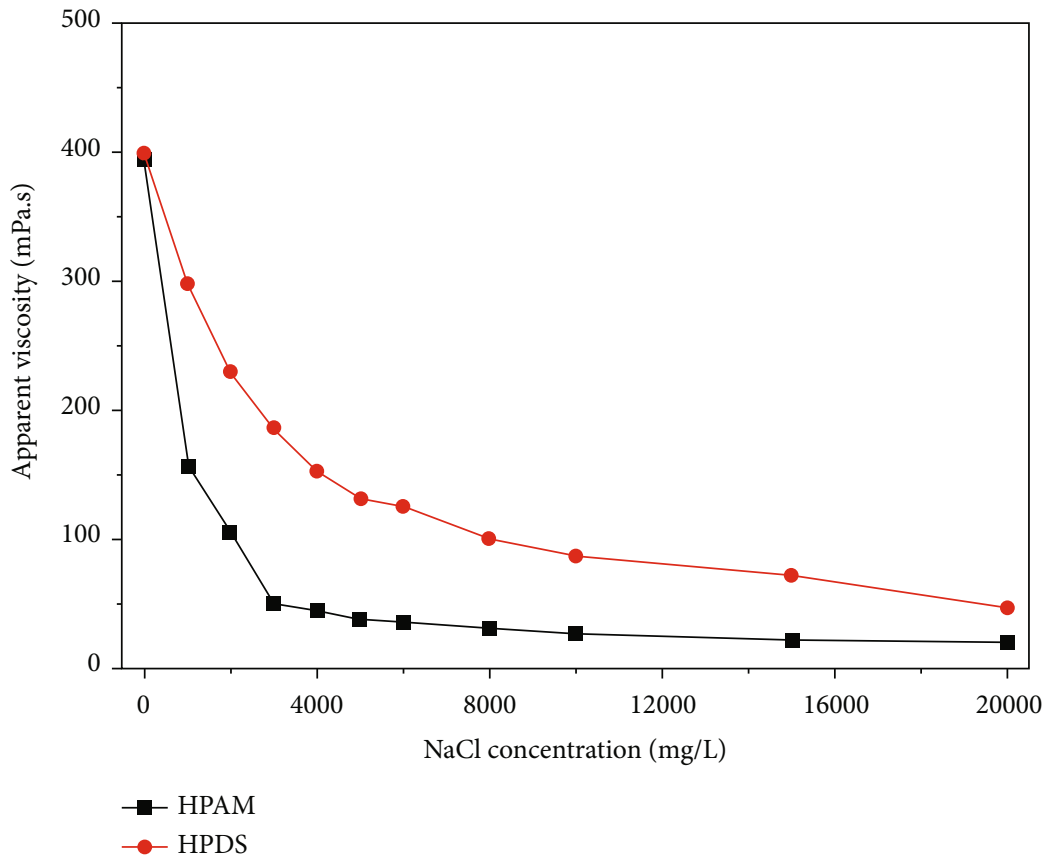

FIGURE 9: Effect of $\mathrm{NaCl}$ concentration on the apparent viscosity of polymer aqueous solution. The apparent viscosity was tested by Brookfield DV-III rheometer at $7.34 \mathrm{~s}^{-1}$.

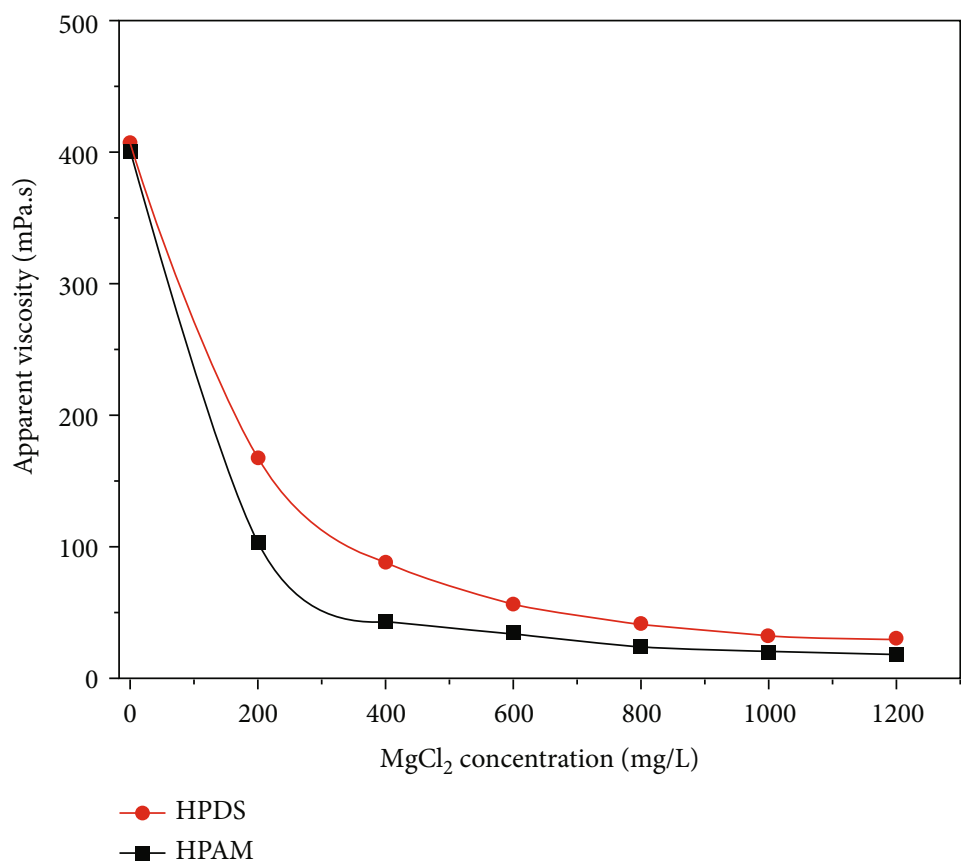

Figure 10: Effect of $\mathrm{MgCl}_{2}$ concentration on the apparent viscosity of polymer aqueous solution. The apparent viscosity was tested by Brookfield DV-III rheometer at $7.34 \mathrm{~s}^{-1}$.

one another by hydrogen-bond interactions in the aqueous solution [27, 28]. However, the intermolecular interaction was unstable, especially under high temperature, resulting in the apparent reduction. However, at any temperature, the viscosity of HPDS was higher than that of HPAM, demonstrating that HPDS revealed better temperature tolerance.
As shown in Table 1, the viscosity after the shearing of HPDS was higher than that of HPMA, especially in highconcentration solution, mainly due to the hydrophobic association among HPDS molecules. When the solution is at high shear rates, most of the network structures and supramolecular aggregations split up. However, when the 


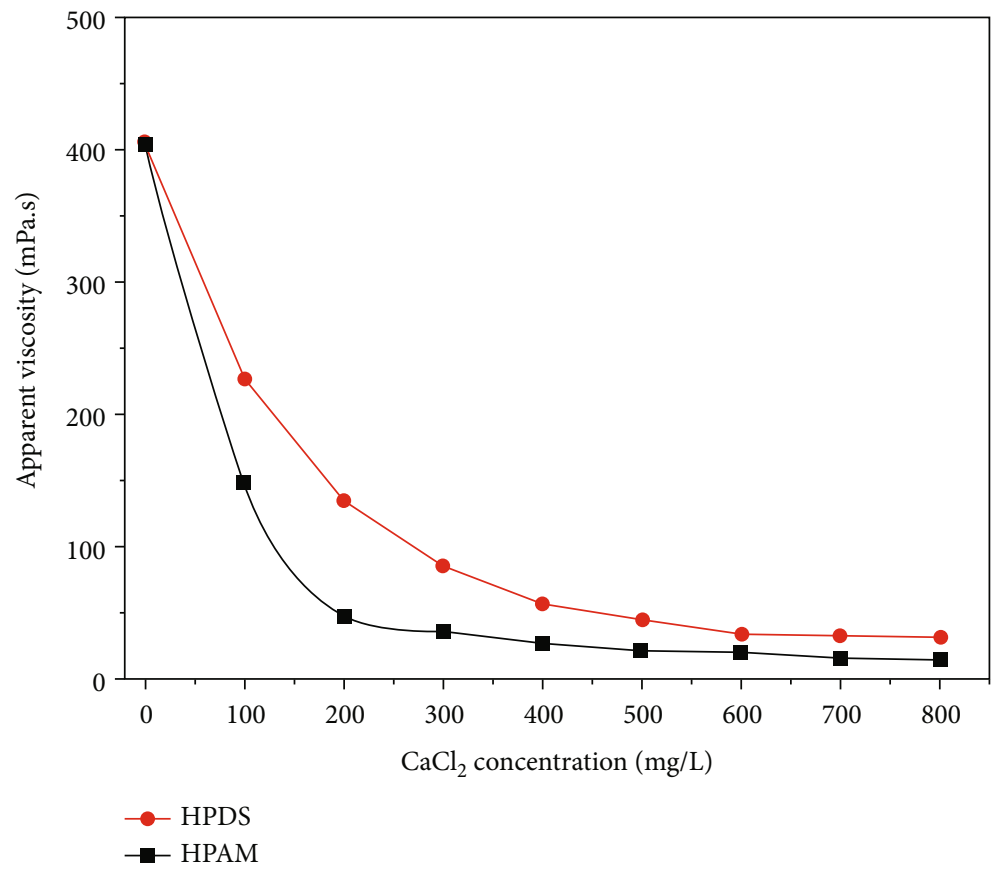

FIGURE 11: Effect of $\mathrm{CaCl}_{2}$ concentration on apparent viscosity of polymer aqueous solution. The apparent viscosity was tested by Brookfield DV-III rheometer at $7.34 \mathrm{~s}^{-1}$.

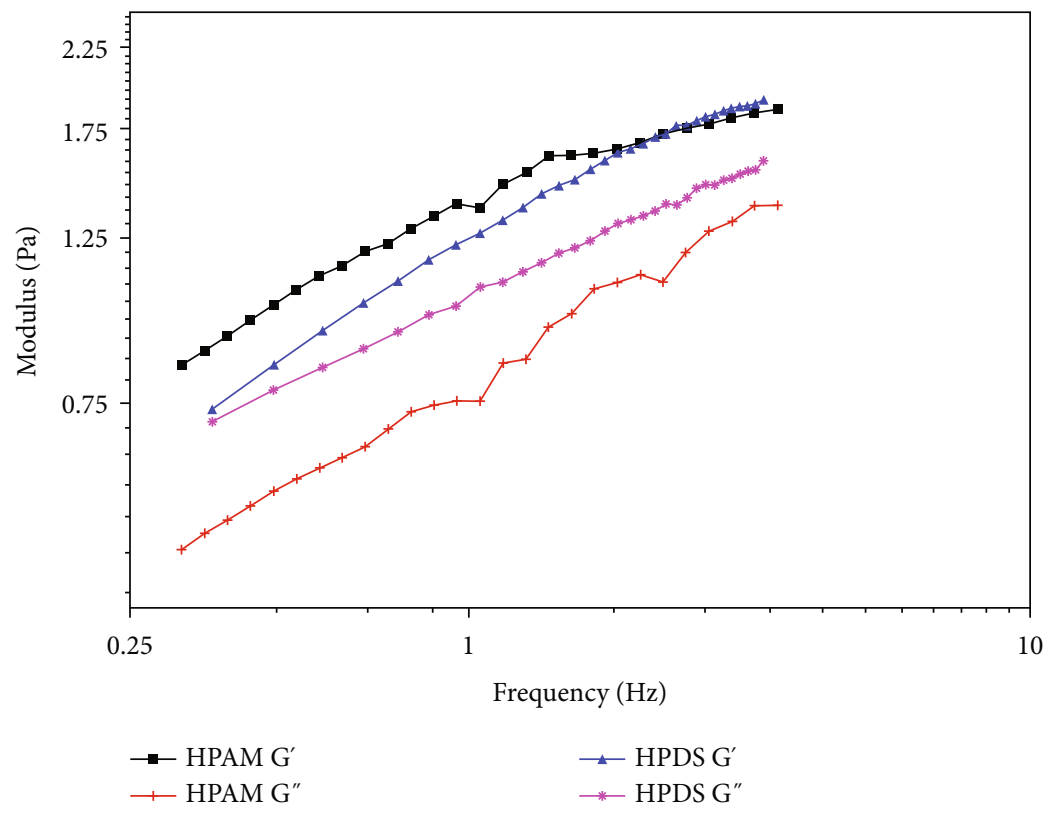

FIGURE 12: Relationship between modulus and frequency.

shear conditions revoke, the molecular chains form new association aggregations and network structures. Due to the large molecular weight and long molecular chain length, at high shear conditions, the HPAM molecular chains are likely to be split into a number of small segments. Thus, the apparent viscosity greatly decreased. The above results demonstrated that HPDS has desirable shear resistance.

The salts, such as $\mathrm{NaCl}, \mathrm{CaCl}_{2}$, and $\mathrm{MgCl}_{2}$, abounding in the formation usually result in high salinity of the reservoir water, a crucial problem for flooding polymer. The relation- ship between brine concentration and apparent viscosity is shown in Figures 9-11. HPDS exhibited higher viscosity under any salinity than HPAM, thereby demonstrating that HPDS was more tolerant to salt brine. The result also revealed that HPDS possessed salt tolerance structures. A possible mechanism is that hydrophobic groups generate association structures with the increase in salt solution polarity, especially among the molecules, which are able to moderate viscosity decline caused by molecular chain curling. Meanwhile, the introduction of salt-insensitive 


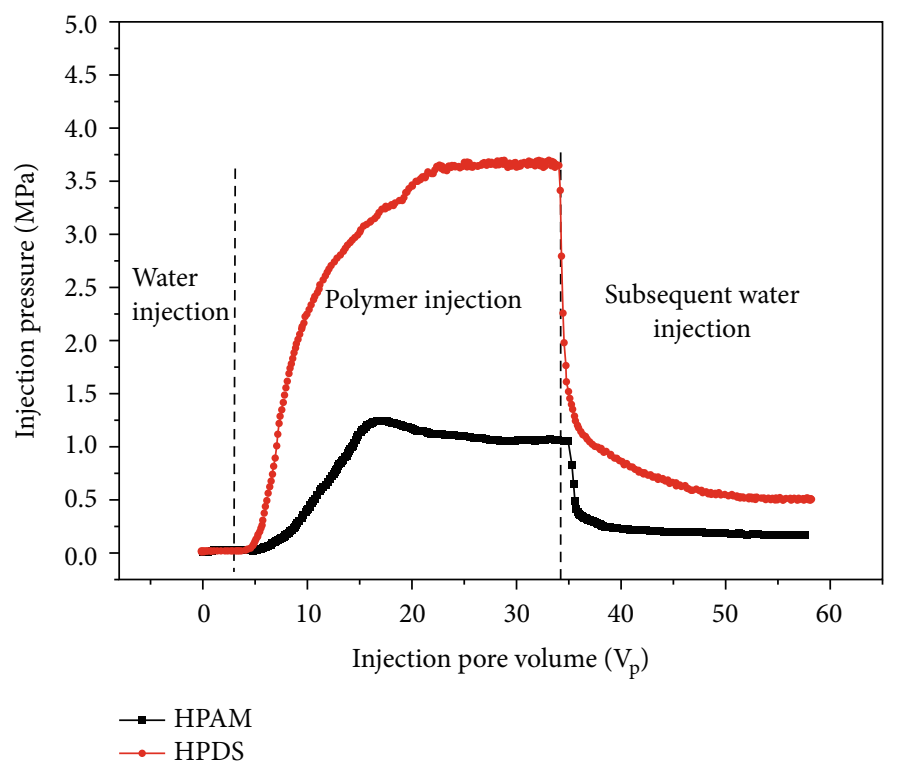

FIGURE 13: Relationship between injection pressure and injection pore volume.

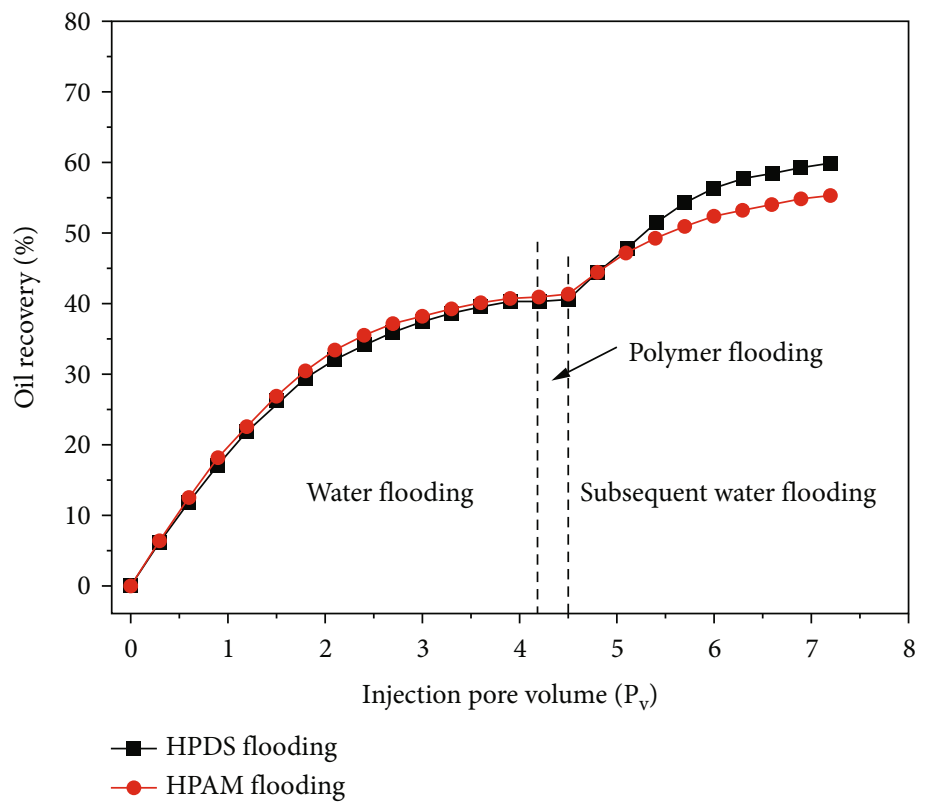

FIGURE 14: Relationship between oil recovery and injection pore volume.

sulfonic groups to the backbone could assemble more bound water molecules to weaken the dehydration of the inorganic salt, thereby causing observable salt-tolerance enhancement $[21,29]$.

3.7. Viscoelasticity of HPDS. Figure 12 shows the viscoelasticity of polymer HPDS and HPAM. The elastic modulus $\left(G^{\prime}\right)$ of HPDS was lower than that of HPAM in low frequency; with the increase in frequency, it showed a sharp increasing trend. When the frequency was higher than $2.3 \mathrm{~Hz}$, the viscous modulus of HPDS was higher than that of HPAM. Comparison of the loss modulus $\left(\mathrm{G}^{\prime \prime}\right)$ of HPDS and HPAM showed that both of them increased with the increase in frequency, and the trend of the former was higher. Therefore, HPDS represented better viscoelasticity.

3.8. Physical Simulation Experiments Analysis. Similar concentrations of HPDS and HPAM solutions and sand-pack models were used in the physical stimulation experiments. As shown in Figure 13, the injection pressure was recorded, and then, RF and RRF were calculated. When the HPDS solution flowed through the sand pack, RF equaled 200.5 and RFF equaled 27.9, while upon injecting HPAM solution, RF equaled 42.4 and RRF equaled 6.8. This finding implied that HPDS was better at establishing flow resistance to control profile in polymer flooding than HPAM, thus expanding the sweep efficiency and improving the ultimate recovery. 
As shown in Figure 14, oil recovery changed when water or polymer solution was injected in the two different homogeneous cores (initial oil saturation of $71.2 \%$ ), which were used to simulate the nonhomogeneity of the reservoir. The experiment results showed that HPDS and HPAM flooding could increase oil recovery, and HPDS flooding performed better by comparison. The first water flooding recoveries of the two experiments were $40.1 \%$ and $41.3 \%$ when water cut reached $95 \%$. Then, flooding agent and subsequent water were injected into the core. Under the same condition, the ultimate recoveries of HPDS and HPAM flooding were $59.9 \%$ and 55.4\%, respectively, and their EORs were 19.8\% and $14.1 \%$, respectively. When injected into the stratum, the polymer solution first entered the layers with high permeability. Then, the water-oil mobility ratio decreased and the injecting pressure rose, which forced more displacement agents to access low-permeability layers that contained much untapped oil. Thus, the sweep efficiency improved and oil recovery increased. The phenomenon above may indicate that HPDS has stronger shear resistance, temperature resistance, salt tolerance, and higher viscosifying ability than HPAM.

\section{Conclusion}

This work introduced a novel polymer HPDS as a flooding polymer. Studies on the properties of this water-soluble polymer revealed that it had good viscosity performance, and the viscosity sharply increased with the increase in concentration, especially when the aqueous solution concentration was thicker than CAC. With the increase in temperature, the polymer viscosity was reduced, while the range was much smaller than that of HPAM, thus displaying great temperature resistance. Meanwhile, the viscosity of HPDS was comparatively higher at any share rate. Considering the hydrophobic groups and sulfonic groups embedded in the polymer backbone, the novel polymer had more diastolic chain segment and network structure than HPAM in brine. In addition, HPDS represented better anchoring ability, especially in high frequency. The simulation experiments showed that HPDS performed better at establishing flow resistance to control profile in polymer flooding, and the oil recovery was up by $19.8 \%$ under $5000 \mathrm{mg} / \mathrm{L} \mathrm{NaCl}$ brine at $60^{\circ} \mathrm{C}$. These findings showed that the novel hydrophobically associating polymer could be an ideal candidate as an EOR chemical to satisfy high-temperature and high-density reservoirs.

\section{Data Availability}

All the data are listed in the manuscript.

\section{Conflicts of Interest}

The authors declare that there is no conflict of interests regarding the publication of this paper.

\section{Acknowledgments}

This work was funded by the Sichuan Science and Technology Program (Applied Basic Research) (2018JY0515), Open Foundation of State Key Laboratory of Oil and Gas Geology and Exploitation (Chengdu University of Technology) (PLC20180103), and Opening Project of Oil and Gas Field Applied Chemistry Key Laboratory of Sichuan Province (YQKF202010).

\section{References}

[1] X. Zhou, Q. Jiang, Q. Yuan et al., "Determining $\mathrm{CO}_{2}$ diffusion coefficient in heavy oil in bulk phase and in porous media using experimental and mathematical modeling methods," Fuel, vol. 263, p. 116205, 2020.

[2] Z. Zargar, S. M. Razavi, and S. M. F. Ali, "Analytical model of steam-assisted gravity drainage (SAGD) process in relation to constant injection rate," Fuel, vol. 265, article 116772, 2020.

[3] D. Belivean, "Waterflooding viscous oil reservoirs," SPE Reservoir Evaluation \& Engineering, vol. 12, no. 5, pp. 689-701, 2009.

[4] Z. Q. Li, J. Hou, W. Liu, and Y. Liu, "Multi-molecular mixed polymer flooding for heavy oil recovery," Journal of Dispersion Science and Technology, vol. 2021, article 1878902, 9 pages, 2021.

[5] Z. Song, Z. Li, F. Lai, G. Liu, and H. Gan, "Derivation of water flooding characteristic curve for high water-cut oilfields," Petroleum Exploration and Development, vol. 40, no. 2, pp. 216-223, 2013.

[6] Z. Song, Z. Li, C. Yu et al., "D-optimal design for rapid assessment model of $\mathrm{CO}_{2}$ flooding in high water cut oil reservoirs," Journal of Natural Gas Science and Engineering., vol. 21, pp. 764-771, 2014.

[7] X. Zhang, C. Lin, Y. Wu et al., "Experimental investigation of the effects of water and polymer flooding on geometric and multifractal characteristics of pore structures," Energies, vol. 13, no. 20, p. 5288, 2020.

[8] H. He, Y. Chen, Q. Yu, X. Wen, and H. Liu, “Optimization design of injection strategy for surfactant-polymer flooding process in heterogeneous reservoir under low oil prices," Energies, vol. 12, no. 19, p. 3789, 2019.

[9] A. M. Firozjaii and H. R. Saghafi, "Review on chemical enhanced oil recovery using polymer flooding: fundamentals, experimental and numerical simulation," Petroleum, vol. 6, no. 2, pp. 115-122, 2020.

[10] F. Wang, H. Yang, H. Jiang et al., "Formation mechanism and location distribution of blockage during polymer flooding," Journal of Petroleum Science and Engineering, vol. 194, p. 107503, 2020.

[11] Q. Yu, Y. Liu, S. Liang, S. Tan, Z. Sun, and Y. Yu, "Experimental study on surface-active polymer flooding for enhanced oil recovery: a case study of Daqing placanticline oilfield, NE China," Petroleum Exploration and Development, vol. 46, no. 6, pp. 1206-1217, 2019.

[12] L. Xue, U. S. Agarwal, and P. J. Lemstra, "Shear degradation resistance of star polymers during elongational flow," Macromolecules, vol. 38, no. 21, pp. 8825-8832, 2005.

[13] R. Zhang, Z. Ye, L. Peng, N. Qin, Z. Shu, and P. Luo, "The shearing effect on hydrophobically associative water-soluble polymer and partially hydrolyzed polyacrylamide passing 
through wellbore simulation device," Journal of Applied Polymer Science, vol. 127, no. 1, pp. 682-689, 2013.

[14] Y. J. Che, J. Cao, H. J. Gong, G. Y. Xu, and Y. Tan, “Dilational rheological properties of fluorocarbon modified poly(acrylamide)s at the air/water surface," Journal of Dispersion Science and Technology, vol. 32, no. 2, pp. 174-184, 2011.

[15] X. J. Liu, W. Jiang, S. Gou et al., "Synthesis and evaluation of novel water-soluble copolymers based on acrylamide and modular $\beta$-cyclodextrin," Carbohydrate Polymers, vol. 96, no. 1, pp. 47-56, 2013.

[16] Z. B. Ye, G. J. Gou, S. H. Gou, W. C. Jiang, and T. Y. Liu, "Synthesis and characterization of a water-soluble sulfonates copolymer of acrylamide and $\mathrm{N}$-allylbenzamide as enhanced oil recovery chemical," Journal of Applied Polymer Science, vol. 128, no. 3, pp. 2003-2011, 2013.

[17] X. J. Liu, W. C. Jiang, S. H. Gou, Z. B. Ye, and X. D. Xie, "Synthesis and evaluation of a water-soluble acrylamide binary sulfonates copolymer on MMT crystalline interspace and EOR," Journal of Applied Polymer Science, vol. 125, no. 2, pp. 1252-1260, 2012.

[18] X. J. Liu, W. Jiang, S. Gou, Z. Ye, and C. Luo, "Synthesis and clay stabilization of a water-soluble copolymer based on acrylamide, modular $\beta$-cyclodextrin, and AMPS," Journal of Applied Polymer Science, vol. 128, no. 5, pp. 3398-3404, 2013.

[19] A. Mehrdad, "Effect of $\mathrm{HCl}$ and solution concentration on the ultrasonic degradation of aqueous solutions of poly (ethylene oxide)," Journal of Polymer Engineering, vol. 28, no. 9, pp. 597-610, 2008.

[20] S. Y. Shao, J. Ding, L. Wang, X. Jing, and F. Wang, "Highly efficient blue electrophosphorescent polymers with fluorinated poly(arylene ether phosphine oxide) as backbone," Journal of the American Chemical Society, vol. 134, no. 37, pp. 1518915192, 2012.

[21] A. Sabhapondit, A. Borthakur, and I. Haque, "Water soluble acrylamidomethyl propane sulfonate (AMPS) copolymer as an enhanced oil recovery chemical," Energy \& Fuels, vol. 17, no. 3, pp. 683-688, 2003.

[22] C. McCormick and L. Salazar, "Water soluble copolymers: 46. Hydrophilic sulphobetaine copolymers of acrylamide and 3(2-acrylamido-2-methylpropanedimethylammonio)-1-propanesulphonate," Polymer, vol. 33, no. 21, pp. 4617-4624, 1992.

[23] N. Lai, W. Dong, Z. Ye et al., "A water-soluble acrylamide hydrophobically associating polymer: synthesis, characterization, and properties as EOR chemical," Journal of Applied Polymer Science, vol. 129, no. 4, pp. 1888-1896, 2013.

[24] X. Y. Wang, Effect of Shear on Microstructure of Polymer Solution, Southwest Petroleum University, 2014.

[25] N. J. Lai, L. Tang, N. Jia et al., "Feasibility study of applying modified nano-SiO2 hyperbranched copolymers for enhanced oil recovery in low-mid permeability reservoirs," Polymers, vol. 11, no. 9, p. 1483, 2019.

[26] Y. Zhang, X. Li, X. Ma, S. Bai, J. Zhang, and R. Guo, "Critical phase separation concentration of acrylamide and 2-acrylamido-2-methylpropanesulfonate copolymers in ammonium sulfate aqueous solution and its influence factors," Colloids and Surfaces A: Physicochemical and Engineering Aspects, vol. 590, p. 124485, 2020.

[27] N. Seetapan, N. Limparyoon, and S. Kiatkamjornwong, "Effect of fire retardant on flammability of acrylamide and 2-acrylamido-2-methylpropane sodium sulfonate copolymer compos- ites," Polymer Degradation and Stability, vol. 96, no. 10, pp. 1927-1933, 2011.

[28] C. S. Yang, K. Shin, and H. K. Jeong, “Thermal analysis of poly(sodium 4-styrenesulfonate) intercalated graphite oxide composites," Chemical Physics Letters, vol. 517, no. 4-6, pp. 196-198, 2011.

[29] D. A. Z. Wever, F. Picchioni, and A. A. Broekhuis, "Polymers for enhanced oil recovery: a paradigm for structure-property relationship in aqueous solution," Progress in Polymer Science, vol. 36, no. 11, pp. 1558-1628, 2011. 